\title{
INFLUENCE OF HUMIDITY AND TRIBOLIUM BEETLE FOOD SOUCE ON THE LIFE HISTORY CHARACTERISTICS OF PREDATOR, XYLOCORIS FLAVIPES (HEMIPTERA: ANTHOCORIDAE)
}

\author{
${ }^{1} \mathrm{~S}$ R Saha, ${ }^{1 *} \mathrm{~W}$ Islam and ${ }^{2} \mathrm{~S}$ Parween \\ ${ }^{1}$ Institute of Biological Sciences and ${ }^{2}$ Department of Zoology, Rajshahi University, Rajshahi 6205, \\ Bangladesh
}

Accepted: 26 September 2011

\begin{abstract}
Life history characteristics of the predator, Xylocoris flavipes reared under four regimes of RH $(30,50$, 70 and $90 \%$ ) on two hosts, Tribolium castaneum and $T$. confusum fed on three artificial diets, were studied. There were significant effects $(\mathrm{P}<0.001)$ of relative humidity on the oviposition period, fecundity, hatchability, developmental time, percentage mortality of immature stages and progeny/ female of the predator on both the hosts. Most of the cases the optimum level of relative humidity was recorded at $70 \%$.
\end{abstract}

Key words: Humidity, Tribolium beetle, Xylocoris flavipes

\section{INTRODUCTION}

Humidity regulates the life cycle of organisms (Andrewartha and Birch 1954), and is usually one of the most important abiotic factors affecting the population dynamics of insects in storage (Sinha 1973, Flinn and Hagstrum 1990). There are many reports available on the impact of climatic factors on the life history characteristics of insects by early workers (Binch 1945, Messenger 1968, Flinn 1991, Monge et al, 1995, Legna et al. 1991, Smith 1994, Monge et al. 1995 and Ouedraogo et al. 1996).

The effects of RH are generally estimably connected with the moisture content of the stored commodities, which essentially regulates eclosion of the pupa and expansion of the adult wings of the insects present at that niche. Hinton (1981) stated that in most insects at normal temperature, there is fairly restricted range of humidity when most eggs will be laid, humidity above or below this optimum range tend to have an adverse effect on oviposition behaviour of the insects. Food is another major factor which influences the normal population growth of the storage insects.

Xylocoris flavipes is associated with the stored -product insect pests in the same niche as predators. So, humidity, temperature and health quality of the prey insects govern over the growth and development of this predator.
The present paper explains the effect of a range of $\mathrm{RH}$ and different host (prey insect) diets and host (prey insect) species on the oviposition period and fecundity of female, hatchability of eggs, mortality of immatures, developmental time and progeny production of $X$. flavipes under the laboratory conditions.

\section{MATERIALS AND METHODS}

Insects used: $X$. flavipes was used as the target insect. The prey insects were Tribolium castaneum and T. confusum.

Host diets: The Tribolium beetles were reared on three artificial diets; yeast, agar and folic acid (Kiji Brand, China) along with a control diet (whole wheat flour). The artificial host diets were mixed with the wheat flour in a ratio of 1:9, 1:9 and 0.3:9.7 respectively. These diets were grouped as I. Yeast+Flour, II. Agar+Flour, III. Folic Acid+Flour and IV. Flour (control).

Food of the predator: The 1st instar larvae and pupae of hosts were provided as food for $X$. flavipes.

Experimentation: The humidity was controlled according to Buxton and Mellanby (1934). Adults of predator (X. flavipes) and hosts ( $T$. castaneum and $T$. confusum) were collected from the stock cultures and kept separately in three beakers. The predator was provided with Tribolium larvae and standard food for the beetles as their foods.

Eggs of $X$. flavipes were collected and reared 
separately on the larvae of two hosts (prey species) until adult emergence. After emergence eight healthy and mated female $X$. flavipes were taken and placed in individual $50 \mathrm{ml}$ glass beakers. These eight beakers were then grouped into two each containing four beakers. In each of the four beakers of one group, 151 st instar larvae $(2-3 \mathrm{~d}$ old) of $T$. castaneum were introduced. These larvae were taken from the four rearing stocks of different (three) artificial diets and the control diet. So, that female predator of each of the beaker was supplied with host larvae which were reared on one of the artificial diet and control food. Similarly, each of the other group of four beakers was supplied with 15 1st instar larvae (2-3d old) of T. confusum reared on different diets. Mouth of each beaker was covered with fine cloth and rubber band to restrict escape of the insects.

These beakers were then kept in desiccators at $30 \% \mathrm{RH}$ for $24 \mathrm{~h}$ for allowing egg lying of the female predator. After $24 \mathrm{~h}$ the females were replaced in separate beakers with host larvae rearing with different diets, for further egg laying and kept at same relative humidity. This procedure was maintained until the death of the female predator.

Similarly, separate experiments were carried out at 50,70 and 90\% RH in desiccators. For each host and artificial diet at each relative humidity level, 15 replications were made. These experiments were carried out at $30 \pm 1^{\circ} \mathrm{C}$ at CT room. From the experiments the following parameters were recorded for $X$. flavipes reared on different diet (prey species) and at different humidity levels.

1. Oviposition period of the female $X$. flavipes

2. Fecundity the female predators

3. Fertility of the predator's eggs

4. Egg to adult developmental time

5. Mortality of immature stages of $X$. flavipes

6. Progeny production of the adult $X$. flavipes

\section{RESULTS AND DISCUSSION}

Oviposition period: The relationship between different supplement foods and oviposition period of $X$. flavipes reared on $T$. castaneum and $T$. confusum at different humidity varied remarkably (Figure 1) and it was significant $(\mathrm{P}<0.001)$ (Table 1). The longest oviposition period of the female predators feeding on $T$. castaneum was $18.07 \pm 0.18$ at $70 \% \mathrm{RH}$ reared on diet II, and the shortest was $5.53 \pm 0.49$ at $90 \% \mathrm{RH}$ reared on diet IV. The longest and the shortest oviposition periods of $X$. flavipes while feeding on $T$. confusum was $17.87 \pm 0.17$ days at $70 \% \mathrm{RH}$ and $5.07 \pm 0.15$ days at $30 \% \mathrm{RH}$, when the diets were II and IV respectively (Figure 2). The optimum RH for longer oviposition time was recorded as $70 \%$ for all diets and on both host species.

Fecundity: It was found that $X$. flavipes reared on $T$. castaneum or $T$. confusum feeding on different artificial diets produced higher number of eggs than when the hosts were reared on control food irrespective of four $\mathrm{RH}$ (Figures 3 and 4). The relationships indicate that food supplements to the prey enhanced egg production in $X$. flavipes. Maximum number of eggs laid by a female on $T$. castaneum $(40.13 \pm 0.19)$ reared on diet II and on $T$. confusum $(38.87 \pm 0.22)$ at $70 \% \mathrm{RH}$. Minimum number of eggs was obtained when the predator preyed on both of the species which were fed on control diet. Both diets and $\mathrm{RH}$ levels, significantly $(\mathrm{P}<0.001)$ increased egg

Table 1: F-values and level of significance calculated for different life history parameters of $X$. flavipes reared on artificial-diet fed $T$. castaneum and $T$. confusum

\begin{tabular}{|c|c|c|c|}
\hline Parameters & sFactors & T. castaneum & T. confusum \\
\hline Ovipositio & Diet & $5.7315, \mathrm{P}<0.001$ & 787.71, $\mathrm{P}<0.001$ \\
\hline $\mathrm{n}$ period & $\mathrm{RH}$ & $1162.27, \mathrm{P}<0.001$ & $1566.92, \mathrm{P}<0.001$ \\
\hline & $\begin{array}{l}\text { Diet } x \\
\text { RH }\end{array}$ & $50.04, \mathrm{P}<0.001$ & $71.44, \mathrm{P}<0.001$ \\
\hline Fecundity & Diet & $9539.35, \mathrm{P}<0.001$ & $8719.19, \mathrm{P}<0.001$ \\
\hline & $\mathrm{RH}$ & $1703.53, \mathrm{P}<0.001$ & $1458.96, \mathrm{P}<0.001$ \\
\hline & $\begin{array}{l}\text { Diet } x \\
\text { RH }\end{array}$ & $90.21, \mathrm{P}<0.001$ & $75.61, \mathrm{P}<0.001$ \\
\hline Hatchabilit & tDiet & $8219.25, \mathrm{P}<0.001$ & $6957.32, \mathrm{P}<0.001$ \\
\hline y of eggs & $\mathrm{RH}$ & $4858.21, \mathrm{P}<0.001$ & $4190.32, \mathrm{P}<0.001$ \\
\hline & $\begin{array}{l}\text { Diet } x \\
\text { RH }\end{array}$ & 467.98, $\mathrm{P}<0.001$ & $394.85, \mathrm{P}<0.001$ \\
\hline Dev. & Diet & $184.68, \mathrm{P}<0.001$ & $176.56, \mathrm{P}<0.001$ \\
\hline & $\mathrm{RH}$ & $356.94, \mathrm{P}<0.001$ & $292.42, \mathrm{P}<0.001$ \\
\hline & $\begin{array}{l}\text { Diet } x \\
\text { RH }\end{array}$ & $2.28, \mathrm{NS}$ & $5.03, \mathrm{P}<0.1$ \\
\hline Mortality & Diet & $23.47, \mathrm{P}<0.001$ & $8.68, \mathrm{P}<0.1$ \\
\hline & RH & $1314.08, \mathrm{P}<0.001$ & $604.94, \mathrm{P}<0.001$ \\
\hline $\begin{array}{l}\text { immature } \\
\text { stages }(\%)\end{array}$ & $\begin{array}{l}\text { Diet } x \\
\text { RH }\end{array}$ & $2.87, \mathrm{NS}$ & $3.34, \mathrm{P}<0.1$ \\
\hline $\mathrm{F}_{1}$ & Diet & $1905.97, \mathrm{P}<0.001$ & $1212.62, \mathrm{P}<0.001$ \\
\hline & $\mathrm{RH}$ & $4150.94, \mathrm{P}<0.001$ & $2736.71, \mathrm{P}<0.001$ \\
\hline female & $\begin{array}{l}\text { Diet } x \\
\text { RH }\end{array}$ & $156.96, \mathrm{P}<0.001$ & $106.51, \mathrm{P}<0.001$ \\
\hline
\end{tabular}


production (Table 1).

Hatchability: The maximum and minimum percentages of hatchability of $X$. flavipes eggs on $T$. castaneum were recorded as $36.47 \pm 0.22$ (reared on diet II) and $8.27 \pm 0.15$ (reared on diet IV) at $70 \%$ and $30 \%$ relative humidity respectively (Figures 5 and 6). The maximum and minimum percentages hatchability of eggs of the predator on $T$. confusum was $36.20 \pm 0.26$ and $7.60 \pm 0.19$ when reared on diet II and IV. The diet III (folic acid+flour) was found to be ineffective in increasing the egg hatchability of the predator. Humidity and diets played significant role in completing embryogenesis and hatching mechanism of the eggs laid by the predator (Table 1).

Developmental Time: Mean development time from egg to adult emergence of $X$. flavipes at different humidity levels took minimum $11.13 \pm 0.13$ days when $T$. castaneum fed on diet II at $70 \%$ RH but maximum was $16.40 \pm 0.13$ days fed on diet IV and $16.53 \pm 10.17$ days on diet II at $30 \% \mathrm{RH}$. Humidity levels affected the developmental time significantly (Table 1). The relationships between the humidity and the developmental time of $X$. flavipes are shown in Figures 7 and 8.

Mortality (\%) among immature stages: Minimum percentage of mortality $(25.74 \pm 0.79)$ of the immature stages of $X$. flavipes was observed when they were reared on $T$. castaneum and $(25.88 \pm 1.05)$ on $T$. confusum on diet II at $70 \% \mathrm{RH}$. Mortality was inversely related with the relative humidity irrespective of diets and host species (Figures 9 and 10). Mortality (\%) of $X$. flavipes differed significantly (Table 1).

Progeny/female predator: Minimum number of $F_{1}$ progeny production on two hosts differed

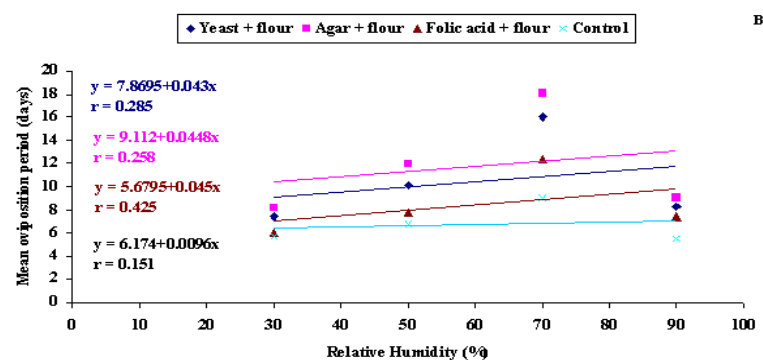

Figure 1. Oviposition period of $X$. flavipes feeding on T. castaneum at different relative humidity $(\%)$.

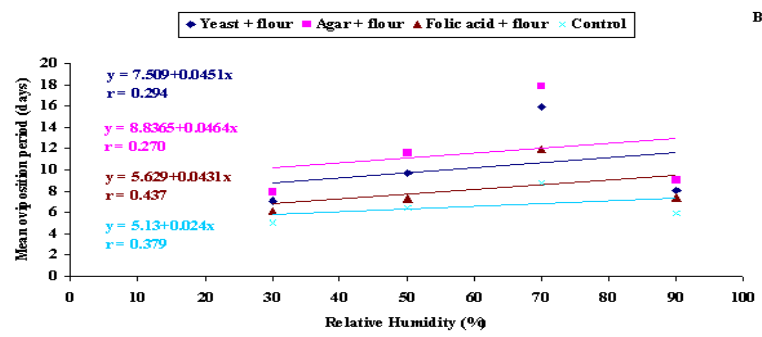

Figure 2. Oviposition period of $X$. flavipes feeding on $T$. confusum at different relative humidity (\%).

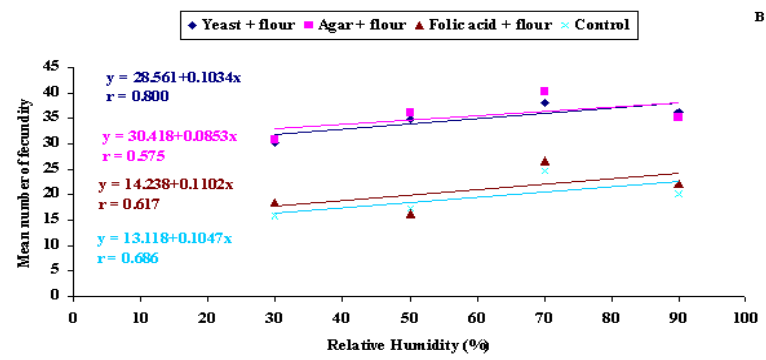

Figure 3. Fecundity of $X$. flavipes feeding on $T$. castaneum at different relative humidity $(\%)$.

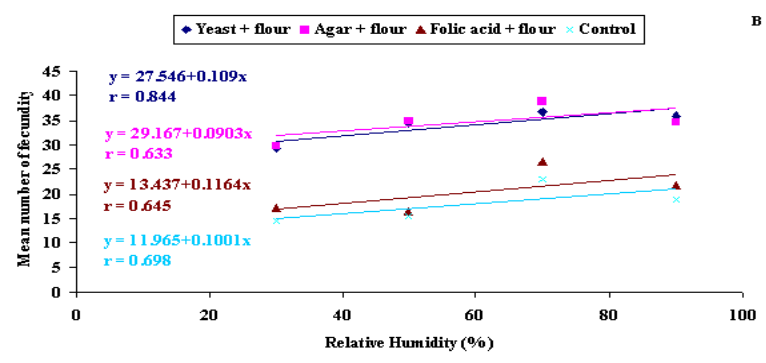

Figure 4: Fecundity of $X$. flavipes feeding on $T$. confusum at different relative humidity $(\%)$.

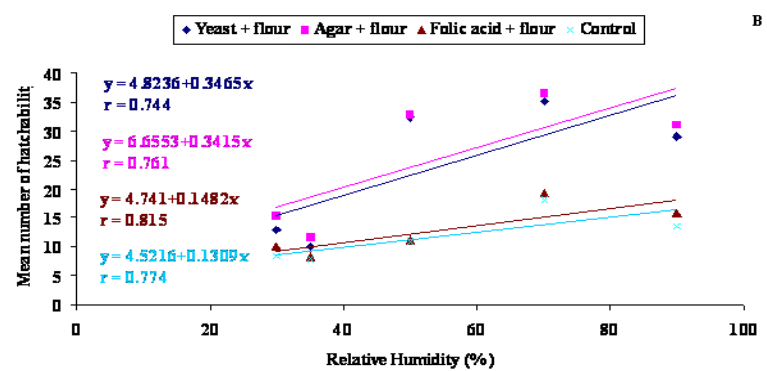

Figure 5. Hatchability of $X$. flavipes feeding on $T$. castaneum at different relative humidity (\%) level.

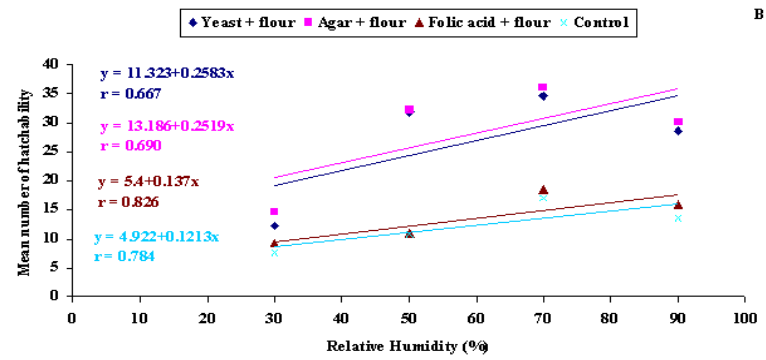

Figure 6. Hatchability of $X$. flavipes feeding on $T$. confusum at different relative humidity $(\%)$ level. 


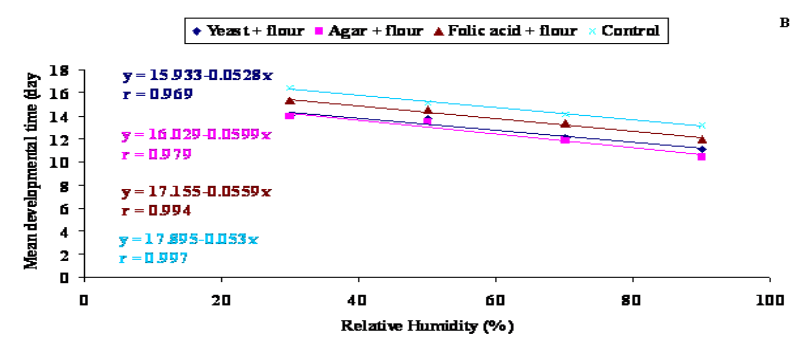

Figure 7. Mean developmental time (day) of $X$. flavipes feeding on $T$. castaneum at different relative humidity (\%).

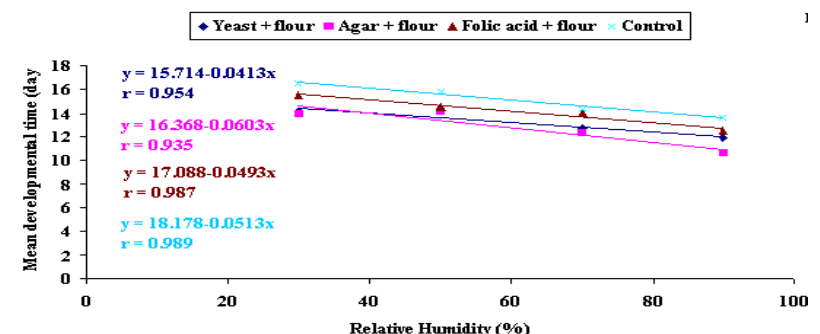

Figure 8. Mean developmental time (day) of $X$. flavipes feeding on $T$. confusum at different relative humidity (\%).

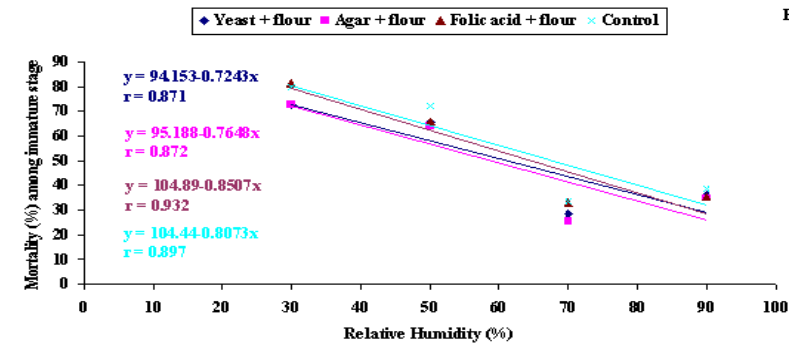

Figure 9. Mortality (\%) among immature stage of $X$. flavipes feeding on $T$. castaneum at different relative humidity (\%).

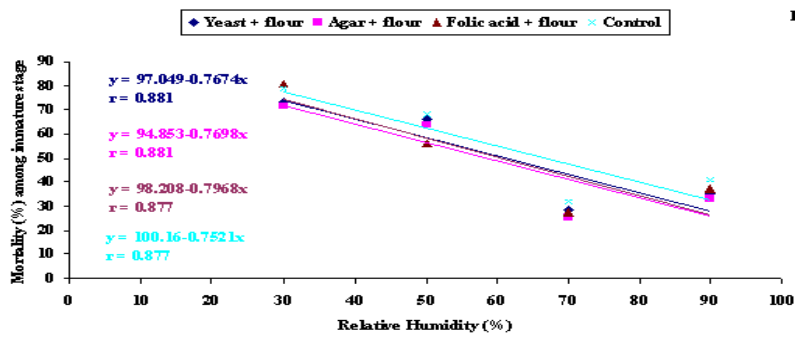

Figure 10.Mortality (\%) among immature stage of $X$. flavipes feeding on $T$. confusum at different relative humidity (\%)

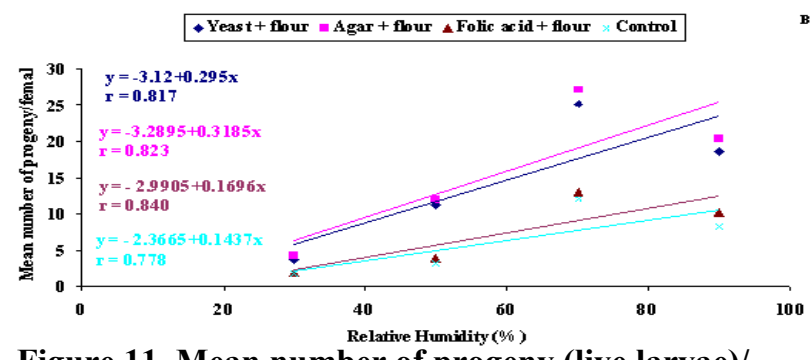

Figure 11. Mean number of progeny (live larvae)/ female of $X$. flavipes feeding on $T$. castaneum at different relative humidity $(\%)$.

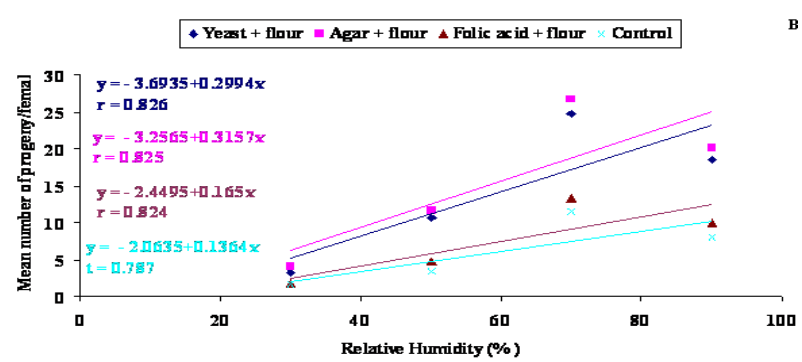

Figure 12. Mean number of progeny/female of $X$.

flavipes feeding and $T$. confusum at different relative humidity (\%).

significantly $(\mathrm{P}<0.001)$ in relation to different foods (Table 1). The most effective food supplement was diet II, which enhanced offspring production in X. flavipes on both hosts, and diet IV was least effective in progeny production of the predator. The maximum number of progeny produced on $T$. castaneum reared on diet II was as $27.07 \pm 0.25$ at $70 \% \mathrm{RH}$, and there were no significant differences of progeny production in between diets III and IV, at any level of humidity (Table 1, Figures 11 and 12).

From the present investigation, it is evident that the population of the predator, $X$. flavipes feeding on $T$. castaneum and $T$. confusum has an optimum level of relative humidity at which the progeny production was the maximum at a minimum developmental time at a constant temperature $\left(30 \pm 1^{\circ} \mathrm{C}\right)$. This result has an importance in mass culture technique for the production of $X$. flavipes when used as a biological control measure in the stores.

The results revealed that life history characters of $X$. flavipes were optimized at $70 \% \mathrm{RH}$ irrespective of host species and host's diet types. RH at high (96-98\%) and low (33.35\%) levels have been reported to shorten the egg laying period of the female $X$. flavipes (Arbogast 1975). In the present experiment, oviposition period was only about five days at both highest (90\%) and lowest (30\%) levels of $\mathrm{RH}$, irrespective of the host species and their diet type. Longer oviposition period of $X$. flavipes was recorded when the hosts were reared on the diet II (agar+flour) at $70 \% \mathrm{RH}$.

Fecundity (total eggs laid) by the predator was adversely affected by low and high RH. The mean number of eggs laid by a single female $X$. flavipes in her life time ranged from 38-40 when reared on Tribolium host feeding on diet 
II at $70 \%$ RH. Whereas, when the predator was reared on Plodia interpunctella, its fecundity adversely affected by high RH (Arbogast 1975).

Diet II increased the egg hatchability of the predator on both hosts. However, maximum $(\%)$ hatching at $70 \% \mathrm{RH}$, but the minimum (\%) hatching was at $30 \% \mathrm{RH}$ when the two hosts were reared on diet IV. The hatching (\%) was positively related with the $\mathrm{RH}$ when the predator was reared on either of two host species. Parajulee et al. (1995) reported that the eclosion rate of Lyctocoris campestris (Hemiptera: Anthocoridae) at $43 \% \mathrm{RH}$ was slightly lowered (70-79\%) than at 58 and $75 \%$ RH.

Developmental time of the predator was not significantly affected by host diets but was negatively related with the humidity. Mortality (\%) among the immature stages of the predator on $T$. castaneum or $T$. confusum was highest at $30 \% \mathrm{RH}$, when the two hosts were reared on diet III. Mortality (\%) was related with the increase of humidity and on diet II. Arbogast et al. (1975) reported that the mortality (\%) among immature stages of $X$. flavipes become relatively high at 35 and $96 \% \mathrm{RH}$.

It was also observed that the total progeny production was linearly increased with the increase $\mathrm{RH}$ from $30-70 \%$, but it decreased at $90 \%$. There were significant differences between RH in progeny production. Okamoto (1972) observed maximum number of progeny of Anisopteromalus calandrae emerged from the host, Callosobruchus chinensis at $70 \% \mathrm{RH}$, which supports the present findings. Cave and Gaylor (1988) noted that in Telenomus reynoldsi (Hymenoptera: Scelionidae) development and progeny emergence were higher at $75 \% \mathrm{RH}$ at a temperature of $28^{\circ} \mathrm{C}$. These results are more or less similar to the present findings.

Maintenance of optimum RH and temperature is essential for mass production of $X$. flavipes. The results indicated that temperature around $30^{\circ} \mathrm{C}$ and $70 \% \mathrm{RH}$ enhance population build up of this predator while feeding on Tribolium larvae. However, host larval diet also play significant role in the culture of $X$. flavipes along with the physical factors of the laboratory.

\section{REFERENCES}

Arbogast RT 1975 Population growth of Xylocoris flavipes: Influence of temperature and humidity. Environ. Entomol. 4(5): 825-831.

Arbogast RT, Carthon M and Roberts JR 1975 Development Stages of Xylocoris Flavipes (Hemiptera: Anthrocolidae) a predator of storage product insect. Ann. Ent. Soc. Am.64: 1131-1134.

Andrewartha G and Birch LC 1954 The Distribution and Abundance of Animals. Chicago, University of Chicago, pp. 782.

Birch LC 1945 The influence of temperature, humidity and density on the oviposition of the small strain of Calandrae oryzae L. and Rhizopertha dominica F. Aust. J Exp. Biol. \& Med. Sci. 23: 197-203.

Buxton PA and Mallanby K 1934 The measurement and control of humidity. Bull. ent. Res. 25:171-175.

Cave RD and Gaylor MJ 1988 Influence of temperature and humidity on development and survival of Telenomus reynoldsi (Hymenoptera: Scelionidae) parasitizing Geocoris punctipes (Heteroptera: Lygaeidae) eggs. Ann. Ent. Soc. Am. 81: 278-285.

Flinn PW 1991 Temperature development functional response of the parasitoid Cephalonomia waterstoni (Hym. Bethylidae) attracting rusty grain beetle larvae. Environ. Entomol. 20:872-876.

Flinn PW and Hagstrum DW 1990 Simulations comparing the effectiveness of various stored grain management practices used to control of Rhyzopertha dominica. Environ. Entomol. 19: 725-729.

Hinton HE 1981 Biology of Insect Eggs. Vol 1, Pergamon Press, Oxford.

Legna A, Thibeaudean C and Hugignard J 1991 Influence of thermoperiod and photoperiod on the reproductive diapause in Brichidius atrolineatus. Phys. Entomol. 16:295-303.

Messenger PS 1968 Bioclimatic studies of the aphid parasite, Praon exsoletum. Effects of temperature on the functional response of females to varying host densities. Can. Entomol. 100:728-740.

Monge JP, Dupont P and Huignard J 1995 The consequences of the interspecific competition between Dinarmus vuilleti on the development of their host populations. Acta Oecologia 16:1930.

Okamoto K 1972 The synchronization of the life cycles between Callosobruchus chinensis (L.) and its parasite Anisopteromalus calandrae (Howard) II. The relationship between the development of the parasite and the 
developmental stage of the host. Jap. J. Ecol. 22:238-244.

Ouedraogo PA, Sou S, Sanon A, Monge JP, Huignard J, Tran B and Credland PF 1996. Influence of temperature and humidity on populations of Callosobruchus maculatus (Coleoptera: Bruchidae) and its parasitoid Dinarmus basalis (Pteromalidae) in two climatic zones of Burkina Faso. Bull. ent. Res. 86:695702.

Parajulee MN, Phillips TW, Thorne JE and Nordheim EV 1995 Life history of immature
Lyctocoris campestris (Hemiptera: Anthocoridae); Effect of constant temperature and relative humidities. Environ. Entomol. 24:889-897.

Sinha RN 1973 Interrelations of physical, chemical and biological variables in the deterioration of stored grains. In Grain storage part of system (Sinha RN and Muvi WE, ed.).pp. 15-47. AVI Publishing, Westport, CT.

Smith L 1994 Temperature influences functional response of Anisopteromalus calandrae parasitizing maize weevil larvae in shell corn. Ann. Ent. Soc. Am. 87:849-855. 